\title{
A Case of Severe and Recurrent Painless Thyroiditis Requiring Thyroidectomy
}

\author{
Hiroaki Ishii ${ }^{a}$ Masahiro Takei $^{a}$ Yoshihiko Sato $^{a}$ Tokiko $_{\text {Ito }}{ }^{b}$ Ken-ichi Ito ${ }^{b}$ \\ Yasuhiro Sakai ${ }^{c}$ Wataru Yumita ${ }^{d}$ Satoru Suzuki ${ }^{a}$ Mitsuhisa Komatsu ${ }^{a}$ \\ ${ }^{a}$ Department of Aging Medicine and Geriatrics, ${ }^{b}$ Division of Breast and Endocrine Surgery, Department of Surgery, \\ and ${ }^{\mathrm{C} D e p a r t m e n t}$ of Molecular Pathology, Shinshu University School of Medicine, Matsumoto, and ${ }^{\mathrm{d}}$ Department of \\ Internal Medicine, Ina Central Hospital, Ina, Japan
}

\section{Key Words}

Thyroid disease $\cdot$ Thyroid function • Thyroid surgery • Thyrotoxicosis

\begin{abstract}
Objective: To report a case of severe and recurrent painless thyroiditis requiring thyroidectomy. Clinical Presentation and Intervention: A 47-year-old man who presented with severe thyrotoxicosis was found to have extremely low radioactive iodine uptake, negative TSH receptor antibodies, and normal C-reactive protein; these findings suggested a diagnosis of painless thyroiditis. Due to the severity and recurrence of thyrotoxicosis, surgical resection of the thyroid gland was performed to prevent a thyrotoxic storm. Histological examination revealed typical lymphoid infiltration of the thyroid gland. Conclusion: This case illustrates that a patient with painless thyroiditis was successfully treated with surgery.

Copyright $\odot 2012$ S. Karger AG, Basel
\end{abstract}

\section{Introduction}

Painless thyroiditis is characterized by thyrotoxicosis, usually of mild to moderate severity, modest goiter, low radioactive iodine uptake, and negative thyroid-stimu- lating hormone (TSH) receptor antibodies. Histologically, the thyroid shows lymphocytic infiltration, at times organized into germinal centers, focal Hürthle cell changes, and/or focal hyperplasia in the thyroid epithelium surrounding the lymphocytes [1]. Painless thyroiditis can be confused with iodine-induced thyrotoxicosis (these patients, however, have pre-existing thyroid diseases such as multinodular goiter), or with factitious thyrotoxicosis (in this case, serum thyroglobulin is very low). The course of painless thyroiditis is usually transient with a hyperthyroid phase that lasts about 2 months before recovery, so that no treatment is typically required. The case presented here is unusual because of the recurrence and severity of the thyrotoxicosis, which required surgical resection of the thyroid gland to prevent a thyrotoxic storm.

\section{Case Report}

A 47-year-old man visited the outpatient clinic of Shinshu University Hospital because of recurrent thyrotoxicosis. Two weeks before the first admission, he consulted his physician because of palpitation and diarrhea. His clinical manifestations and thyroid function indicated profound thyrotoxicosis. Although TSH receptor antibody (TRAb) was negative, thiamazole was initiated because of severe thyrotoxicosis and related manifestations, including atrial fibrillation. The patient's thyroid function

\begin{tabular}{ll}
\hline KARGER & $\begin{array}{l}\text { ○ 2012 S. Karger AG, Basel } \\
1011-7571 / 13 / 0224-0408 \$ 38.00 / 0 \quad \text { Karger }\end{array}$ \\
$\begin{array}{l}\text { E-Mail karger@karger.com } \\
\text { www.karger.com/mpp }\end{array}$ & $\begin{array}{l}\text { This is an Open Access article licensed under the terms of the } \\
\text { Creative Commons Attribution-NonCommercial 3.0 Un- } \\
\text { ported license (CC BY-NC) (www.karger.com/OA-license), } \\
\text { applicable to the online version of the article only. Distribu- } \\
\text { tion permitted for non-commercial purposes only. }\end{array}$
\end{tabular}

Hiroaki Ishii

Department of Aging Medicine and Geriatrics Shinshu University School of Medicine

3-1-1, Asahi, Matsumoto, Nagano 390-8621 (Japan)

E-Mail hiro_i@shinshu-u.ac.jp 

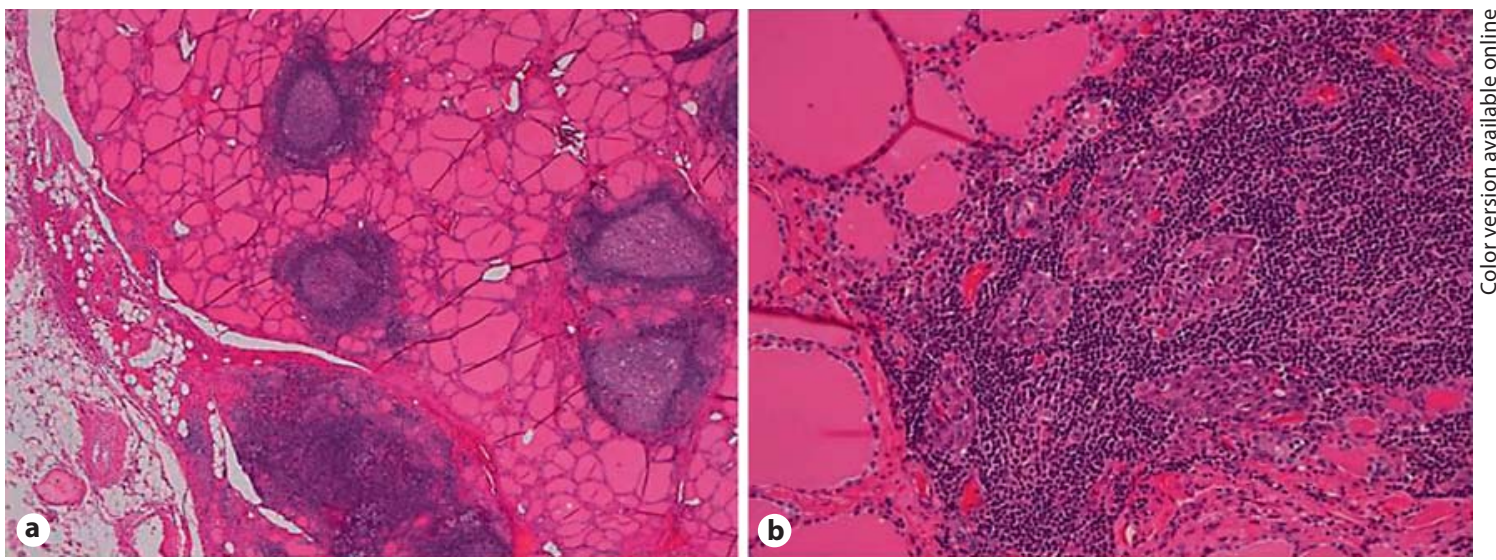

Fig. 1. Pathology of the resected thyroid gland. HE staining showing lymphoid follicular formation with germinal center in the interstitium and lymphocyte infiltration in the follicular epithelium (a). Surrounding lymphoid follicular formation; lymphocyte infiltration was evident in the follicular epithelium (b).

and complaints improved within 3 weeks of commencement of thiamazole administration. After discontinuation of the antithyroid drug, hyperthyroidism recurred, and this cycle was repeated 3 times before the patient was referred to Shinshu University. His body weight decreased from 86 to $68.6 \mathrm{~kg}$ during the 8 months before admission. His physical findings on admission included low-grade fever $\left(37-38^{\circ} \mathrm{C}\right)$, tachycardia (140-160 beats/ min) with irregular rhythm, finger tremor, and excessive sweating. He suffered from severe diarrhea 3 weeks before the second admission. His thyroid gland was not enlarged and showed no spontaneous pain or tenderness. Complete blood count was unremarkable and C-reactive protein level was $0.66 \mathrm{mg} / \mathrm{dl}$. The erythrocyte sedimentation rate was normal. The results of the endocrinological tests were as follows: TSH: $0.012 \mu \mathrm{IU} / \mathrm{ml}$ [normal value (NV): $0.20-4.00$ ]; free T4: $>7.77 \mathrm{ng} / \mathrm{dl}(\mathrm{NV}: 1.00-2.00$ ); free T3: $>32.55 \mathrm{pg} / \mathrm{ml}$ (NV: $2.30-4.00)$; thyroglobulin: $8.4 \mathrm{ng} / \mathrm{ml}$ (NV: 0.0-78.0); anti-thyroglobulin antibody: $30.6 \mathrm{IU} / \mathrm{ml}$ (NV: 0.0-10.0); anti-thyroid peroxidase (TPO) antibody: $86.5 \mathrm{IU} / \mathrm{ml}$ (NV: 0.0-10.0); TRAb: $1.01 \mathrm{IU} / \mathrm{l}$ (NV: 0.00-1.30), and thyroidstimulating antibody (TSAb): $91 \%(\mathrm{NV}:<180 \%)$. Electrocardiography revealed atrial fibrillation and tachycardia. Chest X-ray showed no remarkable abnormalities. One week after the first admission, thyroid uptake was $0.38 \%$ (NV 4-16\%), and the results of thyroid function tests were as follows: TSH: $0.007 \mu \mathrm{IU} /$ $\mathrm{ml}$; free T4: $6.76 \mathrm{ng} / \mathrm{dl}$, and free T3: $8.83 \mathrm{pg} / \mathrm{ml}$. Ultrasound showed no nodules in the thyroid gland, and blood flow was not remarkable. Total thyroidectomy was chosen as an appropriate treatment in this case to control severe thyrotoxicosis and prevent a thyrotoxic storm. Levothyroxine supplementation following resection controlled thyroid function. No relapse occurred after treatment. Diarrhea was improved. The pathological findings demonstrated lymphoid follicular formation with germinal center in the interstitium and lymphocyte infiltration in the follicular epithelium (fig. 1).

Painless Thyroiditis Requiring Thyroidectomy

\section{Discussion}

The distinctive features of this case of painless thyroiditis were the recurrence of the thyrotoxicosis ( 7 times in 1 year) and its severity, which approached that of a thyrotoxic storm given the severe tachycardia and diarrhea. However, Hiraiwa et al. [2] reported a case of adrenal crisis with transient thyroiditis, in which another hormonal deficiency was not apparent. The diagnosis of painless thyroiditis was based on the presence of thyrotoxicosis with low radioactive iodine uptake and negative TSH receptor antibodies. Thyrotoxicosis factitia was included in the differential diagnosis but considered unlikely because the patient asserted that he never took thyroxine, thyroid gland extracts, or foods containing thyroid hormones. Even if the measurement of serum thyroglobulin was low, the histological appearance of the thyroid confirmed the autoimmune pathogenesis of thyrotoxicosis. The treatment of painless thyroiditis is typically limited to observation, given the transient and mild nature of the thyroid dysfunction. $\beta$-Adrenergic blockade is effective for the treatment of symptoms related to thyrotoxicosis. Antithyroid medication and iodide intake are not effective in preventing hormone release from the affected gland. At the beginning of management of this case, we treated with anti-thyroid drugs for a few weeks due to an initial diagnosis of Graves' disease, although TRAb was negative. Prednisolone is an alternative choice to treat painless thyroiditis, although steroid therapy was not initiated because of manic excitement and depressive states in this case. Drastic ablative therapy, such as surgery or radioac-

Med Princ Pract 2013;22:408-410 
tive iodine, is rarely indicated. Although a sufficient absorbed radiation dose is required, radioactive iodide therapy was reported to be effective in some cases of recurrent painless thyroiditis $[3,4]$. There have been three reports of painless thyroiditis treated by thyroidectomy $[5,6]$. Although thyroidectomy is a unique therapy to achieve complete cure, physicians generally hesitate to recommend surgical resection for several reasons. First, this is a rare clinical course among common cases of painless thyroiditis. The second reason is that because thyrotoxicosis due to painless thyroiditis is a process of hypothyroidism, we predicted that thyrotoxic severity would sub- side. Third, exclusion of exogenous thyroid hormone intake is difficult. However, as shown in this case, surgical resection is the most effective form of treatment in cases of severe thyrotoxicosis.

\section{Conclusion}

This was a rare case of severe recurrent painless thyroiditis effectively managed by proactive surgical resection to avoid thyrotoxic crisis.
References
Mizukami Y, Michigishi T, Hashimoto T, Tonami N, Matsubara F, Takazakura E: Silent thyroiditis: a histologic and immunohistochemical study. Hum Pathol 1988;19:423431.

2 Hiraiwa T, Furutama D, Sakane S, Ito M, Imagawa A, Kimura F, Hanafusa T: Isolated adrenocorticotropic hormone deficiency with transient thyroiditis inducing an adrenal crisis. Med Princ Pract 2007;16:230-233.

3 Ohye H: Recurrent severe painless thyroiditis requiring multiple treatments with radioactive iodine. Thyroid 2008;18:12311232.
4 Park HM: Painless thyroiditis and radioactive iodine therapy. Thyroid 2009;19:1013.

5 Aqarwal A, Mishra A, Mishra SK, Aqarwal G, Mithal A, Krishnani N: Recurrent painless thyroiditis requiring total thyroidectomy. J Assoc Physicians India 2000;48:367368.

6 Nikolai TF, Brosseau J, Kettrick MA, Roberts $\mathrm{R}$, Beltaos E: Lymphocytic thyroiditis with spontaneously resolving hyperthyroidism (silent thyroidism). Arch Intern Med 1980; 140:478-482.
Ishii/Takei/Sato/Ito/Ito/Sakai/Yumita/ Suzuki/Komatsu 